It is a shame that the report has failed to pinpoint a dangerous split which I see developing between hospital and extramural mental health facilities. I have purposefully avoided using the term 'community' because it is my belief that all these services are placed in the context of a community, however ill-defined this may be, and that it serves no purpose to introduce false wedges between two aspects of what should be a comprehensive and integrated service. The sooner we stop maligning all hospital or institutional practices, and idealising all extramural ones, the earlier we shall benefit from the fertile mix of creative ideas arising out of both settings - especially if staff have dual responsibilities, both in and out of hospitals. After all, users have the same experience!

I was pleased to notice attention being given to the layout of buildings used for CMHCs. Some may say that this is only a trivial matter, but having worked in unsuitable settings, shouting to get myself heard over the roar of juggernauts, or fighting with colleagues to find a desk where I can write up my notes, I can only concur with the authors' view that issues of design, architecture, accessibility, soundproofing, and I may add, privacy and safety for patients and staff, should be given high priority before people commit themselves to carrying out work there.

The verdict? Good as a debating tool. Poor in scope and depth. A very necessary area for evaluation and research, but perhaps it is too early to write the definitive treatise on policy and practice.

LEONARD FAGIN

608. Community Mental Health Centre,

Leytonstone, London E11

\section{Caring for Huntington's Chorea patients}

Dr Peacock and Professor Harris (1989) recently reported on their study of the cost and location of care for persons suffering from Huntington's disease. The authors are a senior clinical medical officer and a medical geneticist respectively. The patients were ascertained through the North Western Regional Genetic Register based at Manchester.

Their chief findings were:

(a) One quarter of cases were in residential care. Of these, about $70 \%$ were in hospital. Of the latter 39 patients, 24 were in some type of psychiatric ward.

(b) Naturally, patients who were in hospital were older and more chronic than those at home

(c) Neurologists handed over long-term care to psychiatrists.

(d) About half presented with psychiatric symptoms (17\% dementia; $35.5 \%$ "behaviour" problems).

(e) Care at home ( $£ 114$ p.w.) was cheaper than residential care ( $£ 175$ p.w.). (f) Most of those cases in residential care were bereft of adequate care outside (single, divorced, excessive burden, etc.).

The authors called for planned, phased care through day centres to residential care, and they noted the distress caused to relatives and the increase in behavioural problems in patients associated with transfer to psychiatric facilities.

There is the usual introduction about the promises for "prevention and cure" from recent work in recombinant DNA technology. Apart from the huge ethical and social difficulties surrounding such research, it is important to note that Huntington couples still opt for having babies, a very human characteristic, not a few do not understand the advice given by geneticists, and, despite some early hopeful American reports of doubtful methodology, reactions to positive predictive testing can be severe (including suicide) (O'Shea, 1984; O'Shea \& Falvey, 1988). It is also important to note that there is a small false-positive and false-negative reporting rate with these tests, and a sufficient number of willing close relatives from at least two generations are needed to do the test. Foetal testing is positive but its implications are not universally acceptable, although there are trends towards greater acceptance of termination. Genetic engineering, while exciting to the pure scientist and ethicist, is in its infancy. My own imagination extends to defining the gene and its mRNA exactly, and then its protein product(s). The latter may then be modified by chronic drug-taking or its influence reduced by a diet, much in the same way as with PKU.

Although the various national Huntington societies have the support of very dedicated founders, few countries have been able to get more than one or two specialised residencies for their afflicted relatives (O'Shea, 1989). Support groups in general receive scant support from professionals (O'Shea, 1989), and politicians have rarely become interested except for the usual reasons. Huntington's disease exists amid a myriad of other debilitating disorders, some of which are far commoner. The flood of Alzheimer cases in our wards has been met by a totally inadequate political response, and, interestingly, some of us have been blocked from discharging these patients into nursing homes because, we are informed, it is cheaper to maintain them in chronic wards.

No matter what our sums say about cheapness, figures never tell us about the cost to relatives of looking after the severely disabled. Apart from the socio-behavioural manifestations of Huntington's disease, which are often profound (O'Shea \& Falvey, 1988), there is a significant psychopathology associated with just being in a Huntington family (O'Shea, 1984; O'Shea \& Falvey, 1988). 
Everyone is tightening his criteria for the type of patient he (or she) sees as belonging to his workload. This, in my experience, is true of geriatric medicine. Also, general hospitals are transferring back patients to psychiatric hospitals with indecent haste. In Ireland, money and junior staff are scarce commodities. One major area which hasn't been able to say no is the oft' maligned asylum. Psychiatric hospitals struggle on gallantly with diminishing resources to supply a service. Unfortunately, unless public perceptions change, the admission of any dementing patient to a psychiatric institution will remain a time for grieving.

\section{Consultant Psychiatrist}

Brian O'SHEA

Newcastle Hospital

Greystones, Co. Wicklow, Ireland

\section{References}

O'SHEA, B. (1984) Huntington's disease. Irish Journal of Psychiatry, 5, 4-12.

- Huntington's disease: the experiences of voluntary organisations. Psychiatric Bulletin, 13, 409-412.

- \& FALVEY, J. (1988) Huntington's disease: update of the literature. Irish Journal of Psychological Medicine, 5, 61-70.

Peacock, C. E. \& Harris, R. (1989) Huntington's chorea: who cares? Health Trends, 21, 15-17.

CONTEXT Magazine. The Association for Family Therapy, Child and Family Consultation Service, 51 London Road, Canterbury, Kent CT2 8LF.

Context is the new snappy format for the newsletter of the Association for Family Therapy. It is meant to reach a wider audience than previously and it is hoped it will have a separate life of its own from the parental authority of the Journal of Family Therapy.

The editorial team set themselves a heavy and daunting agenda: "But this is not the whole story. People are attracted to family systems ideas because it is an exciting way to psychologise, to share creatively in human problem definition and problem solving; to complement psychodynamic, behavioural or strategic methods with a conceptual language that prevents or reduces the confusions and distortions between the various helping disciplines and the professions. It is indeed a map for negotiating the vast, impersonal social/political edifices humans create for their wellbeing and then become alienated from yet imprisoned within. It focuses directly on that divinely crazy institution the family". Seasoned readers will recognise the institutional language of the systems family therapist emerging at various points in the editorial and elsewhere in the journal. However the writers have insight and comment on the move from the inward looking old newsletter towards the outgoing new magazine. They quote Arthur Koestler characterising the magazine as "holonistic" meaning "an entity at an intermediate level in a hierarchy which can be described as a whole or a part depending on the way it is looked at".

By the time I had read this far in the journal I was fearful that the whole project might grind to a halt by carrying such a weight of ideological baggage. However the magazine is a pleasant surprise. There are helpful articles on how to write papers, a lucid review by David Will on 'feminism, child sexual abuse, and the demise of systems mysticism', and thoughtful contributions on the UK Standing Conference for Psychotherapy as well as the expected information on forthcoming courses and reviews of conferences.

Taking the magazine as a whole rather than its parts, I think it succeeds in its task in that it revived my interest in some of the ways in which systems thinking can cast a new eye on well worn topics. I think it will attract people through its new design without alienating existing members who need an informal forum. Whether the magazine will stand on its own as a publication to be purchased by non members of the Association of Family Therapists I doubt. However I was impressed by the thought and application that had gone into the new venture and I would recommend trainees and established psychiatrists at least to cast an eye on this new offering.

Consultant Psychotherapist

F. R. MARGISON

Department of Psychiatry

Gaskell House, Manchester M13 OEW 